\title{
Excisional Biopsy of Breast
}

National Cancer Institute

\section{Source}

National Cancer Institute. Excisional Biopsy of Breast. NCI Thesaurus. Code C51633.

Removal of tissue from the breast for microscopic examination, involving surgical excision of a portion of the breast. 